We welcome letters to the Editor concerning articles which have recently been published. Such letters will be subject to the usual stages of selection and editing; where appropriate the authors of the original article will be offered the opportunity to reply.

Letters should normally be under $\mathbf{3 0 0}$ words in length, doublespaced throughout, signed by all authors and fully referenced. The edited version will be returned for approval before publication.

(C)2006 British Editorial Society of Bone and Joint Surgery \$2.00 J Bone Joint Surg [Br] 2006;88-B:416-17.

\section{Venous thromboembolism associated with hip and knee replacement over a ten-year period}

Sir,

I read with interest the article by Howie et $\mathrm{al}^{1}$ in the December 2005 issue entitled 'Venous thromboembolism associated with hip and knee replacement over a ten-year period: a population-based study'. The authors have found no evidence of improvement in the incidence of venous thromboembolism or of fatal pulmonary embolism with the increased use of DVT chemoprophylaxis in hip and knee arthroplasty. The authors suggest that their data do not imply that anti-thrombotic prophylaxis and earlier mobilisation regimens have no effect. Their data must also imply that the everincreasing use of chemoprophylaxis has made no difference to the rate of fatal pulmonary embolism. Is the data on length of stay for the hip and knee replacement procedures available over the tenyear period? Their data on day-case and in-patient cataract surgery have shown a significant difference in the venous thromboembolic rate with early mobilisation and discharge.

Early post-operative mobilisation after hip and knee replacements has been accepted as the reason for the decrease in incidence of venous thromboembolic disease. Is it possible therefore, with the data available so far, that we need to pause and review our continuing use of routine DVT chemoprophylaxis for hip and knee replacement surgery?

doi:10.1302/0301-620X.88B3.17613

K. C. KONG, FRCS G

Consultant Orthopaedic Surgeon

King George Hospital, Ilford, UK.

1. Howie C, Hughes H, Watts AC, Scottish Arthroplasty Project. Venous thromboembolism associated with hip and knee replacement over a ten-year period: a population-based study. J Bone Joint Surg [Br] 2005:87-B:1675-80.

\section{Ethics in orthopaedic surgery and Which research is to be believed?}

Sir,

I read with interest the editorials by Benson et $\mathrm{al}^{1}$ and $\mathrm{Carr}^{2}$ in the November 2005 issue entitled 'Ethics in orthopaedic surgery' and
'Which research is to be believed'? I would like to comment, since both deal with the subject of ethics in our profession. The presidents of the English Speaking Orthopaedic Associations and the American Academy of Orthopaedic Surgeons should be commended for their effort to address the subject of ethics in orthopaedics openly and for acknowledging that infractions in this area are widespread.

It has become increasingly evident that the relationship between orthopaedics and industry continues to deteriorate, and ethical infractions arising from this relationship have exploded over the last few decades. Aware of the deteriorating situation, various orthopaedic organisations update their codes of ethics on a frequent basis. Industry, likewise, produces its modified code of ethics, suggesting support for our profession's concerns.

As President of the American Academy of Orthopaedic Surgeons (AAOS) in 1991 to 1992, I devoted much effort to this issue. I held a Board of Directors' retreat to deal with this subject, to which I invited members of other medical disciplines as well as representatives from industry. My hopes of reaching meaningful conclusions never materialised. Nothing of value came out of the retreat, only platitudes about the 'wonderful relationship that had existed between the two groups', 'the great progress that the relationship had spawned', and 'industry's generosity toward orthopaedics'. Subsequent presidents of the organisation have made comparable efforts, but encountered similar failure. The situation today is significantly worse than it has ever been. Codes of ethics are seen as 'paper tigers with no teeth', there simply to be ignored. They seem to concentrate on minor infractions, such as the acceptance of gifts of more than $\$ 100$, while ignoring the bigger picture, such as common 'deals' between industry and individual orthopaedists and their organisations, where millions of dollars are given by industry for the support of its own interests. These deals can result in kickbacks for the use of certain appliances or drugs, huge allowances for participation in industrysponsored 'educational' activities, and endowments of orthopaedic chairs.

The United States' Department of Justice is currently investigating alleged serious irregularities in the relationship between orthopaedics and industry. Among important points in the investigation is industry-sponsored research, which Professor Carr in his editorial, ${ }^{2}$ identified so well. He dwells on the widely-known fact that the results of industry-sponsored research are often egregiously biased and provide conclusive data contrary to that obtained from non-industry-sponsored projects.

There is no easy solution to the growing problem concerning the deteriorating ethical values among orthopaedic surgeons and their representative organisations. However, I have concluded that the single most important feature in its genesis is the fact that orthopaedics has, mainly for the sake of convenience, willingly relinquished to industry the education of its members and in so doing, altered the manner in which the orthopaedic community thinks and practices its profession. 
There should be no doubt that orthopaedic education is conducted today primarily for the purpose of satisfying the marketing needs of industry. It does not take into consideration the harmful effects of such a system to the orthopaedic profession, as well as the resulting unnecessary escalation of the costs of patient care.

The business ethos and nature of industry are being adopted by the medical profession, which with increasing speed looks to profit as its raison d'etre. Unless the orthopaedic profession regains independent control of the education of its members, any hope of preserving the viability of the specialty will soon vanish. If matters continue as they are, we will be forced to admit that we are no longer professionals 'educating' orthopaedists to be physicians or scientists, but technicians 'training' them to be what I have long called 'cosmetic surgeons of the musculoskeletal system'.
Our representative orthopaedic organisation and the appointed directors of orthopaedics in academic institutions, should join forces and make it clear to industry that the current system is unacceptable. The Pandora's Box has been opened and only hope remains; therefore, they should take advantage of this opportunity by acknowledging that while we have also been part of the problem, we are anxious to become part of the solution. doi:10.1302/0301-620X.88B3.17612

A. SARMIENTO, MD
University of Miami School of Medicine, Florida, USA.

1. Benson MKD, Bourne R, Hanley $\mathrm{E}$, et al. Ethics in orthopaedic surgery. J Bone Joint Surg [Br] 2005;87-B:1449-51.

2. Carr AJ. Which research is to be believed? J Bone Joint Surg [Br]2005;87-B:1452-3. 